\title{
Essence, Essence and Essence
}

\author{
Ryan Christensen \\ Department of Philosophy, Brigham Young University
}

I argue that three different notions of essence-temporal, definitional, and modalare all distinct notions, and are all philosophically useful. After defining the different notions, I discuss the philosophical problems each addresses.

Keywords: essence, necessity, temporal essence, Aristotelian essentialism

\section{The Problems of Essence}

There are (at least) two schools of thought concerning essence. One school says that an essential property of a thing is a property that the thing cannot exist without. According to this school, Socrates is essentially human because it is impossible for Socrates to exist and not be human. To use possible-worlds talk, Socrates is essentially human because on every possible world on which Socrates exists, he is human. ${ }^{1}$ Another school says that the essence of a thing is a fundamental property that makes the thing what it is. According to this school, Socrates is essentially human because that is part of what it is to be Socrates. ${ }^{2}$ The philosophers of the second school often frame their discussions by arguing that those of the first school are not talking about essence at all. For example, Oderberg denies that "real essence" has "anything to do with possible worlds" (Oderberg 2007, 12). Philosophers of the first school typically ignore the arguments of those of the second school, but in informal discussion may also deny that those in the second camp are talking about essence.

Corresponding author's address: Ryan Christensen, 4085 JFSB, Brigham Young University, Provo, UT, USA. Email: ryan.christensen@byu.edu.

1 The standard bearers of this school are Putnam and Kripke, and recent examples include Divers (2002) and Mackie (2006).

2 This school was founded by the Aristotelian criticisms of Putnam and Kripke's essentialism (e.g. Witt 1989), and also by Fine's similar criticisms in a series of papers beginning with (Fine 1994). Recent examples include Charles (2000), Oderberg (2007), and Correia (2012). 
Sometimes philosophical debates are substantial, in that both sides agree that there is a certain feature of reality, but disagree over its nature. But sometimes philosophical debates are insubstantial, in that each side is discussing a different philosophically interesting issue and has either found or postulated a feature of reality that explains this issue. ${ }^{3}$ If the essentialist debate is substantial, there is a philosophically interesting feature of reality-essenceand there is disagreement over its nature. If this debate is insubstantial, each side may believe in the entity postulated by the other; there may be no real disagreement over the way things are. Consider, for example, the debate over possible worlds. Some (modal realists) hold that possible worlds are concrete objects, the same in kind as this world; others (some modal ersatzists) hold that possible worlds are maximal consistent states of affairs. What is the nature of this disagreement? If this debate is substantial, there are these philosophically interesting entities-possible worlds-and there is disagreement over their nature. David Lewis rejects this view of the debate:

It is wrong to say that the ersatz modal realists and I agree at least that possible worlds exist, and disagree only about whether those worlds are abstract or concrete... The ersatzers just do not believe in what I call worlds; and sometimes-depending on which view of ersatzism we consider-I just do not believe in what they call worlds. (Lewis $1986,140)$

If Lewis is right, this debate is not substantial. It may be that each side is involved in explaining a different problem, and so postulating different entities: the modal realist is trying to give a reductive account of modality, and the ersatzist is trying to provide a model to illuminate our modal intuitions.

However the debate over possible worlds is best seen, I believe the debate between essentialists is insubstantial. Each side has found a cluster of philosophical issues that can be addressed by something that side calls "essence". The cluster of issues partly overlaps, so it is perhaps natural that both schools use the same term, but the philosophers in the two schools are addressing different philosophical problems, and the notion of essence that they each invoke is different. ${ }^{4}$

3 Some philosophical debates may be neither of these. For example, each side may agree that the feature identified by the other exists, but disagree over which best fills the theoretical role both sides agree on. The modal realist and the ersatzer may both believe in both classes of entities (the concrete worlds and the states of affairs), and there is disagreement over which theory best explains the modal phenomena, and so which class of entities should be called 'possible worlds'. (An ersatzer may believe that the best scientific theory postulates a multiplicity of entities like our world without believing that they are adequate to explain why someone else's properties explain my modal properties.)

${ }^{4}$ In saying this I am not discussing whether either or both kinds of essence are real. It may be that both sides have found a feature of reality, and it may be that either or both are 
I have spoken of two schools, but in fact, there are more than two. I will discuss three different notions of essence, and argue that they are irreducibly different.

\subsection{Essence as constancy amid change}

The first notion of essence has its home in discussion of the problem of change. As often happens in philosophy, more than one problem deserves this label. One such problem could be said like this: There are strong arguments (due primarily to Parmenides and his followers) that change is impossible. And yet it is as obvious as anything is that there is change. How are we to resolve this aporia? Aristotle's answer to this problem is that no change is a what-is coming to be from what-is-not simpliciter; in every change there is a substratum that remains throughout the change. So if Socrates becomes sunburnt, that change is not simply being-sunburnt coming to be from notbeing-sunburnt; it is a change in Socrates. It is one of the marks of Aristotle's genius that many of his solutions seem obvious; this is among those. Clearly Socrates' becoming sunburnt has something to do with Socrates, and not only with the bare being-sunburnt and not-being-sunburnt.

But once we have said that, we still have a further problem. Some changes result in something new coming into being or passing away, and some do not. A sprout grows into a sapling, which grows into a tree, which is cut down and burnt, becoming fire and ash. The change from a sprout to a tree is a profound change, but that change does not create a new thing nor destroy an old thing. The change from a tree to fire and ash is also profound, and this does result in the destruction of the tree. The problem in general is this: What is the difference between a superficial change in an underlying substratum and a passing away? This problem has an instance that is existentially immediate: personal identity across time. Some changes a person undergoes are only accidental: skin color may change in the sun, hair color may change with age, tastes may change with education, but it is a single person undergoing these changes. But what of an injury that alters personality or erases memory? What of some physically minor, or even invisible, change that results in death?

One notion of essence is bound up with this problem, sometimes as its solution, sometimes merely as a label. We could either assume that the distinction between destruction and alteration is well understood, and use that distinction to define essence, or we could assume we understand essence, and use that definition to distinguish between destruction and alteration. ${ }^{5}$

theoretical posits. I wish to set that issue aside.

5 Aristotle's own direction of explanation seemed to differ in different books. In his inquiry 
Among recent writers on essence we can find both approaches. As an example of the former approach, Brody (1973) says "This distinction is one that we are all familiar with... Given this distinction, we are now in a position to introduce a very simple theory of essentialism." Others (e.g., Copi 1954) consider this approach circular, claiming that if we distinguish the kinds of change by reference to the distinction between essence and accident, we cannot then define essence and accident by reference to the kinds of change.

Without deciding which distinction is prior, we can identify the notion of essence relevant to the problem of change. If one considers the destruction/alteration distinction to be prior, one can take the following to be a definition of essence. If one takes the notion of essence as prior, one can take the following as criteria. An accident is a property that changes without causing the destruction of the thing changed; an essence is a property that cannot change without causing the destruction of the thing changed. Mackie (2006) calls this the "Weak Aristotelian sense" of essence:

$A$ is an essence of $B$ iff $A$ is a property of $B$ and, necessarily, if $A$ is a property of $B$ at any time $B$ exists, $A$ is a property of $B$ at all times $B$ exists.

$A$ is an accident of B iff A is a property of B that is not an essence. ${ }^{6}$

This temporal notion of essence is adequte for the problem of change. If we can make sense of the definiens (particularly what it means for something to exist at a time), then we understand this notion of essence. Otherwise we take essence as given here to label the problem: "essence" is the thing that survives every change short of destruction, so if we could only define 'essence' non-circularly, we would be able to distinguish alteration and destruction. Why should we call this a notion of essence? Two reasons: First, there is an august philosophical tradition of speaking of this notion as what Aristotle meant when he introduced the notion of essence (e.g., Copi 1954, Marcus 1971, Mackie 2006). Second, an essence is supposed to be a property

into the nature of substance (ousia) in the Categories, he takes as the most distinctive mark of substance that it survives change (Cat. 4a10). In his renewed inquiry into substance in Metaphysics Z, he may repeat this assertion, depending on how one interprets his claim of temporal priority (Met. 1028a31-33). But when he turns to explaining the difference between destruction and alteration, he seems to take the distinction between substratum (hupokeimena) and accident (pathos) as well understood (De Gen. I.4): "The hupokeimenon is one thing, and the pathos...something else, and...genesis is change of the one, and alteration is change of the other" (Broadie 2004).

6 Often this notion will be expressed with the phrase 'cannot lose' (or 'cannot lose without ceasing to exist'). Such properties as being an adult, or being a parent, or being more than 5 years old, or being a non-virgin, or having visited Vienna-all these are properties that, having once gained them, one cannot lose without ceasing to exist, and yet they do not seem particularly relevant to the problem of change, and do not seem intuitively "essential". 
that is fundamental with respect to some philosophically interesting problem. Because temporal essence is the fundamental property with respect to the problem of change, it can legitimately be called a kind of essence.

\subsection{Essence as explanation}

In Posterior Analytics B 90a31-34 and elsewhere, Aristotle argues that the answer to what a thing is is the answer to why it is, i.e., that essences explain. This is taken to be a central function of essence by Copi (1954), Marcus (1971), Kung (1977), Gorman (2005), and others. It may be what Locke was after in saying, "The real internal, but generally in Substances, unknown Constitution of Things, whereon their discoverable Qualities depend, may be called their Essence." And yet the notion of essence given above will not serve to explain.

A notion that does serve to explain could be called the definitional notion of essence:

$A$ is an essence of $B$ iff $A$ is the most basic fact about $B$, the (possibly molecular) fact about $B$ which, perhaps together with facts not about $\mathrm{B}$, grounds all other explainable facts about $\mathrm{B}$.

$\mathrm{A}$ is an accident of $\mathrm{B}$ iff $\mathrm{A}$ is a fact about $\mathrm{B}$ but not an essence. ${ }^{7}$

This notion of essence has its inspiration in Aristotle's vision of a complete science. The basic idea is that there is a core proposition about that thing from which all the rest follow. This core proposition might be called its definition. Hence, for example, given the definition of a triangle as a closed plane figure bounded by three straight lines, and assuming a background theory of geometry, all other truths about triangles can be deduced, such as that it has three interior angles, and that these three angles are equivalent to two right angles. In general, for each entity there is a core set of true propositions about it. This set of propositions, together with a background set of propositions not about it, entail every true proposition about the entity. ${ }^{8}$

7 On this view an essence is not a property but a proposition. This is, I believe, historically accurate: Aristotle believed that an essence was a definition-a 'logos'-rather than a property. Locke says that the real essence is not a property but "that real constitution of any Thing, which is the foundation of all those Properties" (III.vi.6). But the primary reason to take essence to be this way is that it is propositions, not properties, that entail each other. But the difference is slight. If we prefer to speak of properties being essential, we can say that the essence of $x$ is the property $\mathrm{E}$ such that the proposition that $x$ has $\mathrm{E}$ entails all true propositions about $x$.

8 This approach goes back to Aristotle's Posterior Analytics—see e.g., (Koslicki 2012)—but ignores any of the nuances of Aristotle's positition. As presented here the approach also owes much to Horwich (1998). 
Aristotle's vision is liable to an immediate objection. Apart from mathematical or logical entities, there do not seem to be any examples of properties arranged in this nice axiomatic way. The idea can be salvaged by replacing the concept of entailment, or logical dependence, with the concept of grounding, or ontological dependence. One central idea is that modality, whether of a logical or of a metaphysical kind, makes for the wrong relations. Consider two facts: the fact that gold has atomic number 79 , and the fact that gold melts at $1064^{\circ} \mathrm{C}$. What is the relation between these two facts? This cannot be logical necessity, since the proposition that gold has atomic number 79 does not logically imply anything about gold's melting point. And even if these two facts hold on the same set of worlds, it seems that this gives mere supervenience that does not account for an important feature of the relation between the two facts: gold melts at the temperature it does because of its atomic number; it does not have its atomic number because of its melting point. ${ }^{9}$ This is the idea behind grounding. If we replace the logical notion of implication with the ontological notion of grounding, we can give new definitions of essence. Roughly, A is an essence of B iff A is the fact about B that grounds all the other facts about B.

The intelligibility of such an account of essence turns on the intelligibility of the notion of grounding. I do not have the room to defend the notion here. I will leave it at the intuitive level: gold melts at $1064^{\circ} \mathrm{C}$ because of some more basic fact about gold. ${ }^{10}$ Whatever relation that 'because of' picks out is the grounding relation.

But this is still subject to an obvious objection: It seems that the actual facts about anything depend on more than just the essence of that thing. For example, gold melts at a higher temperature than water. If this fact follows simply from the essence of gold, then the essence of any thing will tell us the essence of all. But then there would not be essences of things, but rather a universally basic fact, a first principle of the world. And further, if we disregard these and consider only the "intrinsic" properties of a thing, only those properties that are about that thing only and nothing else, we cannot even explain all of those. Even the instrinsic properties of a thing do not seem to be wholly determined by the thing's essence. For example, the atomic number of gold determines the melting point of gold, but only given some extra assumptions. If the laws of nature were different, gold might have the same atomic number and yet have a different melting point. So even the instrinsic properties of a thing are determined only in part by the thing's essence. Be-

9 I assume here that the atomic number is the more basic fact. If this should turn out to be wrong, nothing in my argument is affected.

${ }^{10}$ But see, for example, (Fine 2001), (Rosen 2010), (Schaffer 2009), and the various essays in (Correia and Schnieder 2012). 
cause of these considerations, we must say that essence of a thing is at most a partial explanation. Just as the definition of a triangle does not by itself entail the facts about triangles, but only with a background set of assumptions (i.e., the axioms of geometry), so the essence of a thing does not by itself ground all the facts about it, but only with a set of background assumptions. The difference between the essence and the background assumptions is that the essence is a fact about the thing, while the background assumptions are facts not about the thing. ${ }^{11}$

And there is still an obvious objection: Everything has "very accidental" properties that seem unable to be explained by the essence. For example, Socrates is sitting. How is this fact supposed to be explained by Socrates' essence? The obvious response to such an objection is that this notion of essence is restricted to kinds, not individuals. On this notion of essence, Socrates has no individual essence, so such facts are not explicable. What is explicable are the facts about kinds: gold's melting point, conductivity, etc. But this response is insufficient, since even natural kinds have these "very accidental" properties that seem inexplicable by any essential property. It is a fact about gold that the ring on my hand is gold; it is a fact about the species human that this particular human is sitting. So it will not do to require the essence to explain everything. We need to make some restriction on the class of facts that essence must account for.

In her discussion of explanation, Marcus quotes Shylock: "If you pricke vs doe we not bleede? if you tickle vs, doe we not laugh? if you poison vs doe we not die?" This is a list of dispositional facts about humans: they bleed if pricked, laugh if ticked, die if poisoned. The fact about gold's melting point (that it melts if heated to $1064^{\circ} \mathrm{C}$ ) is also dispositional, as are facts about its conductivity, malleability, etc. The essence of a kind must account for all the dispositional facts about the members of that kind. Earlier in his speech, Shylock says, "Hath not a Iew eyes? hath not a Iew hands, organs, dementions, sences, affections, passions." The fact that a human being has eyes is not a dispositional fact, but what we could call a structural fact, and it too must be explained. Similarly, the fact that the interior angles of a triangle sum to two right angles is a structural fact.

Here are two classes of facts-dispositional and structural-that should be explained by essence. The list could be lengthened, but we can leave it open-ended, and call such facts "explainable facts". The essence of a kind should explain every explainable fact about that kind. ${ }^{12}$

${ }^{11}$ A rough test for aboutness: A proposition $p$ is about an entity $x$ if the canonical name of $p$ refers to $x$. So the proposition that gold is malleable is about gold.

${ }^{12}$ There may be more qualifications needed to answer all objections. It may be, then, that this notion of essence is primitive, and the definition above is really a list of connections 
As we did with the temporal notion of essence, we might ask what makes this a notion of essence? And we can give the same answers as before. Many (e.g., Copi 1954, Marcus 1971, Kung 1977) have taken explanation to be the central job of essence, and this notion of essence is central in a philosophically interesting problem-the problem of organizing discrete facts into explanation.

\subsection{Essence as Necessity}

Neither of the notions of essence I have discussed so far is the one that has become familiar from Quine, Kripke, Plantinga, and their followers. ${ }^{13}$ On this notion, essence is defined in terms of necessity:

$A$ is an essence of B iff B is necessarily A. (iff B is A on every world on which $B$ exists.)

$A$ is an accident of $B$ iff $B$ is contingently $B$. (iff $B$ is $A$ on the actual world, but B is not A on some other world.)

(I will call this the modal notion of essence. I do so with some trepidation, since there are also temporal modes. But the term is simpler than its alternatives, and no more confusing. $)^{14}$

The modal notion of essence, along with possible-worlds talk, has turned out to be enormously powerful. It has been used in the philosophy of language (e.g., in the rejection of Frege-Russell semantics, in distinguishing extension from intension, in defining propositions), in the philosophy of sci-

to other concepts.

${ }^{13}$ Despite the fact that Moore defines 'internal relation' in roughly the same way, the contemporary use of the word 'essence' to pick out a modal notion can, I think, be fairly attributed to Quine. Carnap (1956), Copi (1954) and others during the 1940s and '5os understood essence in roughly the definitional sense. The defenders of "Aristotelian essentialism," from Marcus and Kripke on down, have taken their positions in opposition to Quine. And hence, despite protests by Aristotelians and others, essence came to be understood in roughly the way Quine understood it. It is sometimes claimed that Aristotle held the modal notion, but this is dubious. The claim usually rests on the definition of 'accident' (sumbebeekos) as "that which may belong and not belong to one and the same thing" (Topics 102b6-7). But even if the modal word 'may' means something like what it means for Kripke et al. (and not that it hold for only some members of a class, as in Topics B.1, or that it holds only at some times, as in Cat. 4a18-21), Aristotle here has defined not 'accident', but 'merely possible'. In fact, Aristotle gives a wide array of meanings to sumbebèkos: compare this passage with Topics 103b14-19 and Met. 1025a31. On the reading given in both these passages, the fact that the length of any side of a triangle is less than the sum of the other sides counts as a sumbebe kos, but it is a necessary property.

14 'Metaphysical essence' implies that the other notions are not metaphysical, and 'alethic essence' implies that the other notions are not concerned with truth. I could have introduced 'cosmological essence', with a nod to the worlds, but that seemed extravagant. 
ence (e.g., in the discussion of laws and causation), as well as in metaphysics. Since the other concepts of essence are (or at least can be) also modal, this notion has been thought to be fundamental. There are many examples of properties that appear to be essential in all three senses. Triangles have three sides: this property cannot be lost, it implies (given the background theory of geometry) all the properties of a triangle, and it is necessary. So it may be thought, or hoped, that the notions are at bottom the same, and with the success modality has seen in the last few decades, this can be seen as the modal notion.

I think this hope is misguided. But I likewise think the recent tendency to downplay modality is also misguided. The problems that are addressed by temporal and definitional essence are not always addressed by modal essence, and there are problems addressed by modal essence that are untouched by other notions. The different notions of essence are conceptually distinct, and rightly so.

\section{Different Questions}

I have defined three different notions of essence, and hinted at some problems each is supposed to answer. But the fit of notions of essence to problems is a little more complex. There is a cluster of issues that essence has been directed toward, and writers on the topic have not always kept the various strands separate. Every question here has been taken by someone to be answered by essence, but no since notion can answer them all.

1. The question of change: What is the difference between simple alteration and destruction? The answer is supposed to be that essence is preserved in every change short of destruction.

2. The explanation question: If something is so, what explains that it is so? This question could be asked of individuals or kinds: what explains why this individual dog has long ears, or what explains why dogs in general are warm-blooded? The answer is supposed to be that a thing's being so is explained by its essence.

3. The categorization question: Does the world have a single correct set of joints, and if so where does each entity fit into the overall structure? The answer is supposed to be that the essence of each thing is the natural kind it belongs to. ${ }^{15}$

\footnotetext{
${ }^{15}$ Aristotle often takes the essence of a thing to be its genus and difference, as in Posterior Analytics 91a28. See also Locke III.iii.6. Some contemporary philosophers believe in some kind of fundamental structure, but they do not believe this is essence (e.g., Fine 2012, Schaffer 2009, Sider 2011, 267).
} 
4. The identification question: If $a=b$, in what does that identity consist? For example, what is it that makes a thing at $t_{1}$ the same thing as something at $t_{2}$, despite their many differences? The answer is supposed to be that $\mathrm{a}$ and $\mathrm{b}$ have the same essential properties, that all the many differences are only accidental. ${ }^{16}$

5. The discrimination question: If $a \neq b$, in what does that difference consist? For example, what distinguishes the river from its water, or what distinguishes two individuals of the same kind? The answer is supposed to be that they differ in some essential property. ${ }^{17}$

6. The composition question: What makes something a unity, rather than a heap? What is the difference between Socrates, who is a unity, and the mereological sum of the left half of Socrates and the right half of Crito, which is just a heap? The answer is supposed to be that Socrates has an essence, and the mereological sum does not. Again, this question could be asked on individuals or kinds: what is it that makes Socrates a unity, or what is it that makes gold a unity $?^{18}$

7. The identity question: Given some entity, what is it that makes it that entity? This is a deeper question than the identification and discrimination questions, in that these can uniquely specify an entity without giving any foundational account of what it is. The answer is supposed to be that each entity has a unique essence that makes it just that thing. (Once again, this question could be asked either at the individual level or at the level of kinds. $)^{19}$

8. The recognition question: When we are acquainted with a thing, what are we acquainted with? It seems that acquaintance with changing, or contingent, or inessential aspects of a thing cannot count as knowledge of that thing. The answer is supposed to be that knowledge is knowledge of the essence. ${ }^{20}$

${ }^{16}$ Kripke argues in (1971) and (1980) that identity is essential, using 'essential' interchangeably with 'necessary'.

${ }^{17}$ In footnote 56 of Naming and Necessity, Kripke relies on the principle that distinctness is necessary/essential, which, as he points out, is not the same thing as proving that identity is essential since it requires a stronger modal logic.

${ }^{18}$ See Aristotle Met. 1030b6-12, 1041b11-33, (Witt 1989).

${ }^{19}$ Lowe (2012) argues that spacetime trajectory suffices to distinguish physical objects, but that this cannot be essential. Locke apparently meant by "real Essence" some identity condition. It is also, arguably, what Aristotle had in mind.

${ }^{20}$ Aristotle says in Met. 1028a36-40 that knowledge is knowledge of what something is; see also the section above on essence as explanation. But see (Chisholm 1967) for some difficulties with this view. 
Clearly not all of these questions can be answered by every concept of essence. One simple reason for this is that different questions take different entitities to be the bearers of essence. Some take essence to be primarily, or exclusively, something that is had by kinds. The question of whether there is a natural kind for biological species is the question of whether the kind 'elephants' has an essence independent of human interests. It is the elephant, as a kind, that has (or would have) an essence, not any particular elephant. Thus, essence is primarily an answer to the question of categorization. And sometimes the essence of an individual is supposed to be a set of properties that uniquely characterize that individual, including all its modal properties. (In possible-worlds talk: a set of properties that uniquely characterize the individual in all possible worlds.) Thus, essence is primarily an answer to questions of identity. ${ }^{21}$

For Aristotle, the essence of an entity is given by a definition (Top. 101b38). Terms denoting kinds (e.g., 'triangle', 'gold') may be defined, and these definitions give the essence of the thing. But Aristotle also uses individuals as examples of essences (e.g., Met. 1029b14-15). Socrates is a human being; essences of individuals like Socrates, according to the standard view, are only classifying, and so, for example, Socrates and Theatetus have the same essence. On this view, Aristotle invokes essences to answer question 3 , the categorization question. Combined with his epistemology, essence also plays a role in answering questions 2 and 8. But, on this view, Aristotle's essences play no individuating role, so questions 4-7 are out when asked about individuals. (When asked about kinds, Aristotle might say that horses and humans are different because they have different essences-one is a four-footed animal and one is a two-footed animal. $)^{22}$

Locke defines essence as "the Being of any thing, whereby it is what it is. And thus the real internal, but generally in Substances, unknown Constitution of Things, whereon their discoverable Qualities depend, may be called their Essence" (III.iii.15). Locke fully admits that individuals have

${ }^{21}$ Certainly one may believe in both kind essences and individual essences. But it is also consistent to believe in individual essences but not kind essences, and kind essences but not individual essences. Aristotle is often said to hold the latter view. For the former, one may hold that kind is not an essential property of any individual. This individual is, in fact, an elephant, but only accidentally. One may hold that individual essences are simple properties, not classes or conjunctions of simple properties. (This is one view that goes under the name haecceity. Each individual's essence is its haecceity, but that essence does not organize the world into kinds.)

${ }^{22}$ But Aristotle also has some hints that essences are to play an individualizing role. As noted above, Aristotle considers question 6 in Met. 103ob6-12, 1041b11-33. Witt (1989) argues that the traditional account of Aristotle's essence "is wrong in holding that the most important function of form or essence is to explain species membership," and argues that, instead of 7,6 and 8 are the central questions Aristotle takes essence to answer. 
these essences-and hence that essence is supposed to answer the identity question (7). And yet he insists that this is unknowable except in the case of "simple Ideas and Modes" (e.g., 'triangle'), and so cannot answer 2 and 8 . Thus, all our categorizing and sorting and attempts at understanding are relative to our own language or conceptual scheme. When Locke speaks of a "nominal essence," he acknowledges that the word 'essence' is taken to be involved in the work of categorization and understanding, but he denies that this "essence" is a mind-independent feature of reality. ${ }^{23}$

Fine (1994) is very Lockean. He is explicit about his interest in essence:

It is not my view that the modal account fails to capture anything which might reasonably be called a concept of essence. My point, rather, is that the notion of essence which is of central importance to the metaphysics of identity is not to be understood in modal terms or even to be regarded as extensionally equivalent to a modal notion.

Fine here declares that the notion of essence he will discuss is addressed to the identity question ( 7 ). The modal notion is too weak to answer this question, and some of these other questions, such as categorization and explanation, are to be answered by ground, which for Fine is a different notion. (And thus none of the three notions of essence listed above is Fine's.)

What about the modalists? Which of these questions do they believe to be answered by essence? Not all, of course, agree on every particular, and some of these issues are controversial. But, since the modal notion is defined in terms of necessity and identity, the questions of identity and distinctness ( 4 and 5) are the primary concerns of a theory of essence. In Lecture III of Naming and Necessity, Kripke argues that a particular human being necessarily had her origin in a particular pair of gametes, and that a particular table necessarily was formed from a particular chunk of matter. His arguments for these views turn on intuitions that if the individual were different in the relevant way, it would be a different individual. Kripke is not interested in giving a full list of essential properties, but a natural extension of what he says here is that essence answers the categorization question (3): if Elizabeth's gametes are essential, so too is her species. But this is not a forced move. One may agree with Kripke that origins are essential but disagree that there are biological kinds. Because of vagueness issues and the constant flux of species, species categorization is to some extent arbitrary, even if individuals have their origins essentially. The composition question (6) for natural kinds also seems a natural extension of the modal view, but

${ }^{23}$ Locke's Essay is long and repetitive, and there are passages that support a different reason of essences than I have given. While I am no expert on Locke, I believe this reading is justified by the text. 
the composition question for individuals seems largely unrelated. And in sharply distinguishing the a priori from the necessary, Kripke clearly denies that the recognition question (8) has anything to do with essence.

There is some disagreement about whether the modal notion is intended to address the explanation question (2). That is clearly the idea behind the claims that, e.g., water is necessarily $\mathrm{H}_{2} \mathrm{O}$ : the necessary coincides with the explanatorily basic. And yet many have seen this as a separate claim. Cowling (2013), for example, says "the modal view of essence does not hold... that essential properties furnish use with answers to what-questions." It is a substantial metaphysical claim that modality has anything to do with explanation. Charles (2000) agrees, identifying three main theses in Kripke-style "modern essentialism" about natural kinds:

1. Gold has a fundamental feature, of a type grasped by scientists, which determines its other features.

2. Gold has one and the same feature in all possible worlds in which it exists which fixes the identity of the kind.

3. The fundamental feature in (1) is the identity-fixing feature in (2).

The third thesis is the substantial claim that the modal notion is capable of answering the explanation questions posed in the first thesis. I agree with Cowling and Charles: the modal notion of essence cannot answer the explanation question; it is intended for different things.

\section{Different Kinds of Essence}

Different philosophers have taken essence to answer different questions. How do we account for this difference? One explanation might be that there is a single thing, essence, that each philosopher is trying to explain. Clearly the mere fact that they differ on some details is not enough to say that they are after different things. Two philosophers may hold the modal notion of essence, say, and disagree over whether essence, thus understood, is explanatory. On such a question there may be a right answer. But this explanation is insufficient as an explanation of the disagreements among all the philosophers. If one philosopher says that essence is whatever answers question $\mathrm{A}$, and another philosopher says that essence is whatever answers question $\mathrm{B}$, and nothing can answer both questions, then it is false to say they are both trying to explain the same thing. I claim that none of the notions is more basic (more natural, more "joint-carving") than another. Of course, it is open to someone to insist that one notion of essence-either one I have listed above or a different one-is more basic. But there is no obvious reason to do so. None of the notions above implies the others, so none is logically 
prior. None is a restriction of any other. For the first two notions, at least, there is good reason to think that the "definitions" above are really characterizations, that these notions of essence are explanatorily prior to their definientia. Someone might insist that one of these notions is more fundamental, but there seems to be no compelling reason to do so.

My own view is that these are all real kinds of essence. They are related closely enough that none has a better claim to be the notion of essence, yet they are distinct enough that there is no central kind. What needs to be explained, then, is why they all deserve to be called the same thing. Why not just say that there are three separate notions that, due to historical accident, have all come to be called 'essence', and the sooner we find different names for them the better? Cowling (2013), for example, takes the modal notion of essence as basic, and since it cannot answer "what-questions," the answer to these questions must be something other than essence, something he calls 'nature'. Kung (1977), similarly, takes the Aristotelian view of essence as basic, on which essence is explanatory, and dismisses anything that is inconsistent with it. I find such a procedure rash. It is not merely historical accident that led all these to be called 'essence.' They each are attempts to explain the "most important part" of a thing. Since importance is relative, there are different notions of essence: one that picks out the fact that is most important with respect to explanation, one that picks out the attribute that is most important in terms of longevity, and so on. 'Essence' is not simply a homonym like 'bank', with various unrelated concepts called the same thing by happenstance. Essence is what gets at the kernel, the gist, the fundamental, the most important. ${ }^{24}$

We have many different conceptions of essence, and I would hate to be forced to do without any of them. It is useful to have a notion that picks out those properties that persist across the lifespan of a thing. It is useful to have a notion that picks out an individual's uniqueness and discriminates it from every other individual. It is useful to have a notion that picks out a thing's place in the structure of the world. And it is useful to have a notion that describes the nature of that structure itself. Useful notions all, and all legitimate claimants to the the title of essence. But, unsurprisingly, there is no single notion that can do all these jobs. So we have essence, essence, and essence.

${ }^{24}$ This inchoate notion is not specific enough to make a generic sense of essence that is perfectly natural, from which the other notions can be defined by restriction. 


\section{Acknowledgments}

Thanks to Daniel Graham, Tuomas Tahko, and anonymous referees for comments on earlier drafts of this paper.

\section{Bibliography}

Broadie, S. (2004). On Generation and Corruption i.4: Distinguishing alteration-substantial change, elemental change, and first matter in GC, in F. de Haas and J. Mansfeld (eds), Symposium Aristotelicum: Aristotle's On Generation and Corruption I, Oxford University Press, Oxford, pp. 123150.

Brody, B. A. (1973). Why settle for anything less than good old-fashioned aristotelian essentialism?, Noûs 7(4): 351-365.

Carnap, R. (1956). Meaning and Necessity, University of Chicago Press, Chicago.

Charles, D. (2000). Aristotle on Meaning and Essence, Oxford University Press, Oxford.

Chisholm, R. M. (1967). Identity through possible worlds: Some questions, Noûs 1(1): 1-8.

Copi, I. M. (1954). Essence and accident, The Journal of Philosophy 51(23): 706-719.

Correia, F. (2012). On the reduction of necessity to essence, Philosophy and Phenomenological Research 84(3): 639-653.

Correia, F. and Schnieder, B. (eds) (2012). Metaphysical Grounding: Understanding the Structure of Reality, Cambridge University Press, Cambridge.

Cowling, S. (2013). The modal view of essence, Canadian Journal of Philosophy 43(2): 248-266.

Divers, J. (2002). Possible Worlds, Routledge, New York.

Fine, K. (1994). Essence and modality, in J. E. Tomberlin (ed.), Philosophical Perpectives VIII: Logic and Language, Ridgeview Pub Co, pp. 1-16.

Fine, K. (2001). The question of realism, Philosophers' Imprint 1(1): 1-30.

Fine, K. (2012). Guide to ground, in F. Correia and B. Schnieder (eds), Metaphysical Grounding: Understanding the Structure of Reality, Cambridge University Press, Cambridge, pp. 37-80.

Gorman, M. (2005). The essential and the accidental, Ratio 18(3): 276-289. 
Horwich, P. (1998). Truth, 2nd edn, Clarendon Press, Oxford.

Koslicki, K. (2012). Essence, necessity and explanation, in T. Tahko (ed.), Contemporary Aristotelian Metaphysics, Cambridge University Press, Cambridge, pp. 187-206.

Kripke, S. (1971). Identity and necessity, in M. K. Munitz (ed.), Identity and Individuation, New York University Press, pp. 135-164.

Kripke, S. (1980). Naming and Necessity, Harvard University Press, Cambridge, Mass.

Kung, J. (1977). Aristotle on essence and explanation, Philosophical Studies 31(6): 361-383.

Lewis, D. (1986). On the Plurality of Worlds, Blackwell, Oxford.

Lowe, E. (2012). Asymmetrical dependence in individuation, in F. Correia and B. Schnieder (eds), Metaphysical Grounding: Understanding the Structure of Reality, Cambridge University Press, Cambridge, pp. 214-233.

Mackie, P. (2006). How Things Might Have Been, Clarendon Press, Oxford.

Marcus, R. B. (1971). Essential attribution, The Journal of Philosophy 68: 187202.

Oderberg, D. S. (2007). Real Essentialism, Routledge, New York.

Rosen, G. (2010). Metaphysical dependence: Grounding and reduction, in B. Hale and A. Hoffmann (eds), Modality: Metaphysics, Logic, and Epistemology, Oxford University Press, Oxford, pp. 109-36.

Schaffer, J. (2009). On what grounds what, in D. Chalmers, D. Manley and R. Wasserman (eds), Metametaphysics, Oxford University Press, Oxford, pp. $357-83$.

Sider, T. (2011). Writing the Book of the World, Oxford University Press, Oxford.

Witt, C. (1989). Substance and Essence in Aristotle, Cornell University Press, Cornell. 